\title{
EVALUASI LAHAN BASAH BUATAN VEGETASI MANGROVE DALAM MENGURANGI PENCEMARAN LINGKUNGAN (Studi Kasus di Desa Kepetingan Kabupaten Sidoarjo)
}

\author{
Widayati Kusumastuti*, Boedi Hendrarto* , Danny Sutrisnanto** \\ Program Studi Ilmu Ilmu Lingkungan, Program Pascasarjana Universitas Diponegoro Semarang \\ **Jurusan Teknik Kimia Fakultas Teknik Universitas Diponegoro Semarang
}

*Email: danny@undip.ac.id

\begin{abstract}
ABSTRAK
Hutan mangrove sebagai salah satu sumber daya alam yang mempunyai peranan penting, salah satunya adalah untuk mengatasi pencemaran lingkungan. Di daerah penelitian di Desa Kepetingan Kabupaten Sidoarjo terdapat lahan mangrove di areal pertambakan yang dimaksudkan menjadi lahan basah untuk fitoremidiasi bagi air tambak. Penelitian ini dimaksudkan untuk mengevaluasi kemampuan lahan basah mangrove yang sudah ada sekaligus menilik kemungkinan pengembangannya sebagai wetland buatan. Penelitian yang dilaksanakan selama Juni hingga Desember 2007. Sedangkan pengambilan sampel dilakukan pada tanggal 25, 26 dan 27 Juni 2007. Penelitian ini mengkaji efektifitas lahan basah kaitannya dengan kualitas air dan sedimen yang diteliti. Penelitian ini merupakan penelitian deskriptif. Pengumpulan data dilakukan melalui observasi, pengukuran langsung kualitas air, kualitas sedimen dan pengambilan sample vegetasi lahan basah buatan. Pengambilan sampel air dan sedimen dilakukan pada tempat-tempat yang dianggap mewakili keadaan Sungai Kepetingan, lahan basah dan area tambak secara keseluruhan. Sampel diambil pada lima stasiun yaitu stasiun sungai, stasiun inlet, stasiun lahan basah, stasiun outlet dan stasiun muara. Pengambilan sampel dilakukan sebanyak tiga kali pada tiap stasiun. Studi struktur dan komposisi mangrove dilakukan dengan menggunakan metode yang merupakan modifikasi dari cara yang digunakan oleh Mueller Dumbois dan Ellenberg (1974). Pengamatan pasang surut dilakukan di satu titik pada lokasi yang representatif dengan lama pengamatan 30 × 24 jam. Pengamatan dilakukan dengan cara memasang alat ukur ketinggian muka air yang dibaca setiap jam. Pengukuran kecepatan aliran dilakukan secara berjajar pada beberapa titik dalam satu lokasi. Pengukuran dilakukan dengan menggunakan current meter. Hasil penelitian menunjukkan bahwa lahan basah mangrove di Kepetingan memiliki tipe dataran pantai yang didominasi jenis Rhizopora sp, Avicennia Sp dan Excoecaria Sp. Dalam area lahan seluas $7.762 \mathrm{~m}^{2}$ frekuensi kehadiran tertinggi kategori pohon, sapling dan seedling lahan basah berkisar $0.45-0.55 \%$. Species yang berada di dalam wetland adalah Avicennia Sp dengan kerapatan 64 Ind/Ha. Pengukuran parameter fisika kualitas air menyatakan efisiensi telah tercapai karena wetland mangrove mampu mengatasi kekeruhan dan dapat meningkatkan kecerahan. Kemampuan lahan basah sangat tinggi dalam mengatasi kelimpahan kadar nitrat dan fosfat. Kadar nitrat berkurang menjadi $0.13 \mathrm{mg} / \mathrm{l} \mathrm{di}$ outlet dari semula $0.63 \mathrm{mg} / \mathrm{l}$ di inlet dan kadar fosfat menjadi $0.05 \mathrm{mg} / \mathrm{l}$ di outlet dari semula $0.35 \mathrm{di}$ inlet. Kadar tembaga (Cu) di outlet mencapai $0.053 \mathrm{mg} / \mathrm{l}$ dari semula $0.042 \mathrm{mg} / \mathrm{l}$ di inlet. Kadar BOD mencapai maksimum di dalam wetland yaitu sebesar $76 \mathrm{mg} / \mathrm{l}$. Lahan berhasil mereduksi kadar cadmium (Cd) menjadi 0.017 di outlet dari awalnya 0.026 di inlet. Logam Pb di sedimen, lahan mangrove berhasil mengurangi konsentrasi dari $25 \mathrm{mg} / \mathrm{kg}$ dan $45 \mathrm{mg} / \mathrm{kg}$ menjadi hanya $18 \mathrm{mg} / \mathrm{kg}$ di outlet. Cu di sedimen, konsentrasi tertinggi justru berada di dalam lahan yaitu sebesar $277 \mathrm{mg} / \mathrm{kg}$ namun sedikit menurun menjadi $219 \mathrm{mg} / \mathrm{kg}$ pada pengukuran di outlet. Lahan basah berfungsi untuk menangkap dan mengendapkan logam-logam berat.
\end{abstract}

Kata Kunci: Type your keywords here, separated by semicolons; or comma, 


\section{PENDAHULUAN}

Kerusakan lingkungan perairan dapat disebabkan tertimbunnya bahan-bahan pertanian, peternakan maupun industrialisasi. Di Desa Kepetingan terdapat Sungai Kepetingan dan banyak sekali lahan tambak yang mengandalkan pengairan dari sungai tersebut. Hingga saat ini di daerah penelitian masih terdapat lahan mangrove dan areal pertambakan. Lahan mangrove tersebut telah dimodifikasi menjadi area fitoremidiasi bagi air tambak. Akan tetapi sampai saat ini belum banyak diteliti kemampuan mangrove sebagai tanaman filter dan pereduksi pencemaran. Penelitian ini dimaksutkan untuk mengevaluasi kemampuan lahan basah yang sudah ada sekaligus menilik kemungkinan pengembangannya sebagai lahan basah buatan. Untuk mendekati masalah tersebut terlebih dahulu harus dilakukan penelitian awal dan pengambilan contoh zat-zat pencemar dan konsentrasi zat tersebut di perairan. Selain itu perlu pula dilakukan analisis terhadap zat pencemar, meliputi seberapa tinggi kadarnya di perairan dan apakah melebihi Baku Mutu atau tidak. Selanjutnya dilakukan analisis seberapa besar perubahan kadar zat pencemar saat sebelum, sedang berada dan sesudah meninggalkan lahan basah. Dengan demikian dapat dievaluasi tingkat keberhasilan lahan basah dalam mereduksi zat pencemar. Kualitas air mencakup parameter fisika dan kimia. Parameter fisika yaitu aspek suhu dan salinitas. Parameter kimia meliputi $\mathrm{pH}$, oksigen terlarut (OD), Biochemical Oxygen Demand (BOD) dan kadar logam. Logam berat di antaranya merkuri $(\mathrm{Hg})$, timbal $(\mathrm{Pb})$, arsenic $(\mathrm{As})$, cadmium $(\mathrm{Cd})$, kromium (Cr), Nikel (NI) dan Tembaga (Cu). Kualitas sedimen mencakup logam-logam berat yang terkandung dalam sedimen diantaranya timbal dan tembaga.

Fitoremediasi adalah teknologi pembersihan, penghilangan atau pengurangan polutan berbahaya menggunakan bantuan tanaman. Dalam pengaplikasian teknik ini tanaman yang dipilih dipelihara dalam suatu lahan basah buatan. Lahan basah buatan di perairan yang dekat dengan laut biasanya ditanami mangrove. Mangrove adalah tumbuhan yang bisa hidup di daerah intertidal sekaligus memiliki berbagai kelebihan dalam menyaring zat polutan (Khiatuddin,2003). Mangrove adalah tanaman yang sangat cocok untuk dibudidayakan di areal pertambakan.
Ekosistem mangrove mampu menghilangkan sebagian bahan pencemar dari tambak. Penilitian di Hongkong menunjukkan tanah di hutan mangrove mampu menghilangkan senyawa fosfor dan logam yang berasal dari air limbah (Tam dan Wong dalam Khiatudin,2003). Penelitian mengenai akumulasi dan distribusi logam berat pada mangrove simulasi oleh Nora F.Y Tam dan Yuk Shan Wong (1997) menyatakan bahwa kandungan logam berat lebih banyak ditemukan di perakaran. Ini menunjukkan bahwa komponen sedimen mangrove memiliki kapasitas yang besar untuk menyimpan logam berat. Akan tetapi kemampuan untuk menahan logam berat ini tergantung dari usia tanaman dan produksi biomassa (Tam et all,1997).

\section{METODE PENELITIAN}

Penelitian dilaksanakan pada tanggal 25, 26 dan 27 Juni 2007. Lokasi penelitian adalah areal tambak termasuk lahan basah berisi mangrove yang berbatasan langsung dengan Sungai Kepetingan. Areal ini terletak di Desa Kepetingan, Kecamatan Buduran, Kabupaten Sidoardjo, Provinsi Jawa Timur. Lokasi pengambilan sampel air dianggap mewakili keadaan Sungai Kepetingan, lahan basah dan area tambak secara keseluruhan. Sampel diambil pada lima stasiun yaitu badan sungai Kepetingan (St Sungai), daerah aliran masuk dari Sungai Kepetingan (St Inlet), area lahan basah mangrove (St Wetland), daerah aliran keluar dari lahan basah (St Outlet) dan muara Sungai Kepetingan (St Muara). Pengambilan sampel air dilakukan secara berurutan dari stasiun I, II, III, IV dan terakhir stasiun V. Perlakuan ini diambil menyesuaikan dengan waktu terjadinya pasang dan surut air yang mengaliri tambak dikarenakan pada saat sampling dilakukan pintu air untuk input dan output masih menjadi satu. Metode sampling parameter-parameter kualitas air adalah :

1. Pengukuran temperatur dan salinitas mempergunakan instrumen water quality checker; HORIBA, yang mampu mengukur parameter kualitas air, seperti: salinitas, $\mathrm{pH}$, DO, TDS, suhu, kedalaman, konduktivitas, turbiditas.

2. Pengukuran parameter nitrat, nitrit, fosfat, amoniak, $\mathrm{Hg}, \mathrm{Cd}, \mathrm{Pb}, \mathrm{Cr}, \mathrm{Cu}$, Pestisida, BOD, COD, silikat, TSS dilakukan dengan pengambilan contoh air dengan menggunakan botol Nansen. 
Sampel sedimen diambil dengan menggunakan grab sampler yang kemudian dimasukkan ke dalam plastik klip sebanyak 250 gram untuk masing-masing titik pengambilan sampel. Sampel sedimen diambil pada tiap stasiun dengan menggunakan alat Ekman grab. Sampel sedimen yang diambil merupakan sedimen pada bagian permukaan dasar perairan yang memiliki ketebalan kurang dari $20 \mathrm{~cm}$. Contoh sedimen kemudian ditampung dalam botol polyetylen. Selanjutnya tempat sampel dibungkus dengan kantong plastik dan selanjutnya dimasukkan kedalam Cool box untuk diangkut menuju laboratorium.

Lokasi pengambilan sampel flora tersebar di 5 (lima) stasiun dan dilakukan secara purposif. Studi struktur dan komposisi mangrove dilakukan dengan menggunakan metode yang merupakan modifikasi dari cara yang digunakan oleh Mueller Dumbois dan Ellenberg (1974). Pada tiap stasiun ditetapkan 3 titik pengambilan sampel yang diharapkan dapat mewakili stasiun tersebut. Selanjutnya pada masing-masing titik sampling tersebut dibuat plot berukuran $10 \mathrm{~m} \times 10 \mathrm{~m}$ untuk pengambilan data pohon ( $\mathrm{dbh} \geq 4 \mathrm{~m}$ ), subplot 5 $\mathrm{m} \times 5 \mathrm{~m}$ untuk data sapling $(1 \mathrm{~m} \leq \mathrm{dbh}<4 \mathrm{~m})$ dan subplot $1 \mathrm{~m} \times 1 \mathrm{~m}$ untuk seedling (anakan) dengan ketinggian $<1 \mathrm{~m}$ (Gambar 1.1).

Data yang diambil tersebut dianalisa untuk diketahui nilai Frekuensi kehadiran, Kerapatan (K) dan Basal Area (BA). Pengamatan pasang surut dilakukan di dua titik pada lokasi yang representatif dengan lama pengamatan 30 × 24 jam. Analisis hasil pengamatan berupa tinggi muka air rata-rata dan konstanta-konstanta pasang surutnya.

10

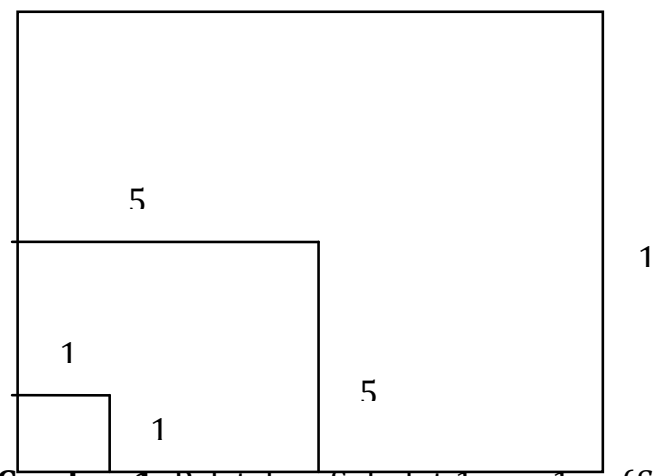

Gambar 1. Peletakan Subplot $1 \mathrm{~m}$ x $1 \mathrm{~m}$ (Seedling) dan Subplot $5 \mathrm{~m}$ x $5 \mathrm{~m}$ (Sapling) dalam Plot $10 \mathrm{~m} \times 10 \mathrm{~m}$ (Pohon) untuk sampling flora

\section{HASIL DAN PEMBAHASAN}

Hasil pengamatan lapangan terhadap jenis mangrove di wilayah Desa Kepetingan adalah:

Tabel 1. Komposisi vegetasi mangrove di kawasan Sidoardjo :

\begin{tabular}{|l|l|l|}
\hline \multicolumn{1}{|c|}{ Famili } & \multicolumn{1}{c|}{ Spesies } & \multirow{2}{*}{ Keterangan } \\
\cline { 1 - 2 } Avicenniaceae & Avicennia marina & \multirow{2}{*}{ Komponen Mayor* } \\
\cline { 1 - 2 } Arecaceae & Nypa fruticans & \multirow{2}{*}{ Kompon } \\
\cline { 1 - 2 } Rhizoporaceae & Rhizophora apiculata & \\
\hline Euphorbiaceae & Excoecaria agallocha & Komponen Minor* \\
\hline Acanthaceae & Acanthus illicifolius & Asosiasi* \\
\hline
\end{tabular}

Dari gambar grafik frekuensi kehadiran mangrove menunjukkan bahwa kehadiran mangrove baik itu kategori pohon, sapling dan seedling paling banyak berada di lahan yang menjadi area lahan basah itu sendiri. Rhizopora mempunyai akar penunjang yang tumbuh dari batang. Dari penelitian Silva (1990) dan Lacerda (1993) terbukti bahwa Rhizopora dan Avicennia mampu menyerap polutan logam dengan baik. Rhizopora dapat menyerap $\mathrm{Cu}, \mathrm{Pb}$, $\mathrm{Cr}, \mathrm{Cd}$ dan $\mathrm{Ni}$. Bahkan untuk $\mathrm{Pb}$ dan $\mathrm{Cr}$ penyerapan dilakukan oleh semua bagian tumbuhan. Begitu pula untuk Avicennia, mampu mengakumulasi $\mathrm{Cu}, \mathrm{Pb}$ dan $\mathrm{Zn}$ dalam jaringan akar dengan level yang sama dan atau lebih tinggi dari konsentrasi sedimen di sekitarnya (Mac Farleane,2003).

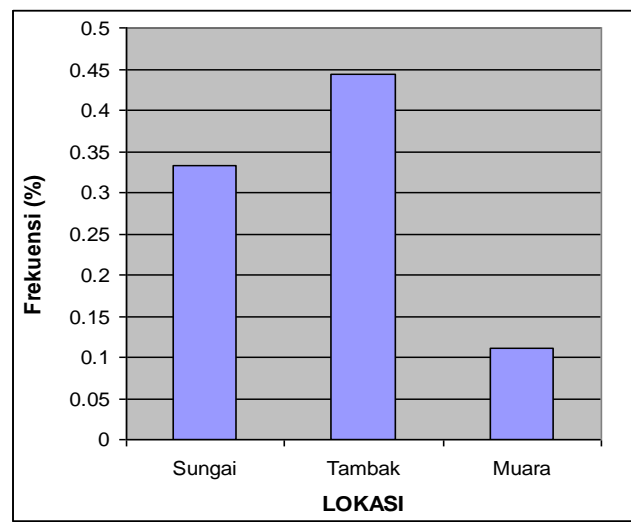

Gambar 2. Frekuensi Kehadiran Mangrove Kategori Pohon 


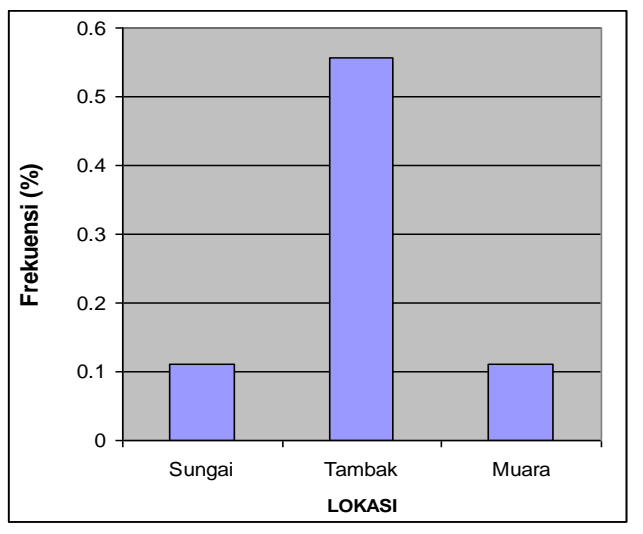

Gambar 3. Frekuensi Kehadiran Kategori Sampling

Tabel 2. Kerapatan dan Basal Area tiap spesies Pohon

\begin{tabular}{|l|l|l|}
\hline Species & K (ind/ha) & $\begin{array}{l}\text { BA } \\
\left(\mathbf{m}^{\mathbf{2}}\right)\end{array}$ \\
\hline Inlet & & \\
\hline Rhizopora apiculata & 100 & 0.89 \\
\hline Excoecaria agallocha & 533 & 145.60 \\
\hline Avicennia marina & 200 & 44.26 \\
\hline Jumlah & $\mathbf{8 3 3}$ & $\mathbf{1 9 0 . 7 5}$ \\
\hline Tambak & & \\
\hline Avicennia marina & 64 & 289.65 \\
\hline Jumlah & $\mathbf{6 4}$ & $\mathbf{2 8 9 . 6 5}$ \\
\hline Sungai & & \\
\hline Excoecaria agallocha & 867 & 75.15 \\
\hline Jumlah & $\mathbf{8 6 7}$ & $\mathbf{7 5 . 1 5}$ \\
\hline
\end{tabular}

Sumber : Hasil Perhitungan Sampel

Tabel 3. Kerapatan dan Basal Area Untuk Tiap Spesies Sapling

\begin{tabular}{|c|c|c|}
\hline Spesies & $\begin{array}{c}\mathbf{K} \\
\text { (ind/ha) }\end{array}$ & $\mathrm{BA}\left(\mathrm{m}^{2}\right)$ \\
\hline \multicolumn{3}{|l|}{ Inlet } \\
\hline Rhizophora apiculata & 19 & 5.28 \\
\hline Excoecaria agallocha & 20 & 6.68 \\
\hline Nypa fruticans & 4 & 0.00 \\
\hline Jumlah & 43 & 11.96 \\
\hline \multicolumn{3}{|l|}{ Sungai } \\
\hline Excoecaria agallocha & 36 & 30.85 \\
\hline Jumlah & 36 & 30.85 \\
\hline
\end{tabular}

Sumber : Hasil Perhitungan Sampel
Pada penelitian ini, dalam lahan basah sebesar $7.762 \mathrm{~m}^{2}$ untuk kategori pohon nilai kerapatannya adalah 64 individu Avicennia marina. Basal area juga turut mempengaruhi kemampuan serap mangrove akan bahan pencemar. Lahan dengan kerapatan tinggi belum tentu basal areanya besar. Basal area Avicennia marina yang terdapat di dalam lahan basah mencapai $289.65 \mathrm{~m}^{2}$. Dengan kerapatan 64 ind/Ha dan basal area $289.65 \mathrm{~m}^{2}$ lahan basah telah mampu mereduksi bahan pencemar.

Fungsi lain dari tumbuhan mangrove dalam mengurangi pencemaran adalah kapasitasnya sebagai pendukung kehidupan mikro organisme pengurai limbah. Banyaknya organisme mikro yang hidup dalam lahan basah akan meningkatkan kinerja pembersihan secara menyeluruh, dikarenakan organisme mikro tersebut mencerna bahan pencemar dalam rangka memperoleh energi.

Agar dapat berbicara mengenai kemampuan ataupun efisiensi suatu lahan basah maka harus dikemukakan data kerapatan pohon dan basal area mangrove di lahan tersebut.

\section{Analisis Kualitas Air}

Pengambilan data kualitas air dilakukan di 5 titik, yaitu sungai, inlet, lahan basah, outlet dan muara, dengan hasil pengukuran kualitas air terdapat pada Lampiran I, halaman 11.

Kandungan logam berat $\mathrm{CHg}, \mathrm{Cd}, \mathrm{Cu}, \mathrm{Cr}$, dan $\mathrm{Pb}$ ) menunjukkan bahwa nilai 3 jenis logam berat $(\mathrm{Hg}, \mathrm{Cr}$, dan $\mathrm{Pb})$ masih berada di bawah ambang batas yang disyaratkan menurut Keputusan Kementrian Lingkungan Hidup No 51 tahun 2004. Sedangkan dua jenis logam berat (Kadmium/Cd dan Tembaga/Cu) kandungannya menunjukan nilai di atas ambang batas dari KepMen KLH No 51 Tahun $2004(\mathrm{Cd}=0.001 \mathrm{mg} / \mathrm{L}$ dan $\mathrm{Cu}=0.008 \mathrm{mg} / \mathrm{L}$ ). Akan tetapi meskipun hasil keluaran dari outlet sebagian besar melebihi baku mutu lahan basah, tidak serta merta bisa disimpulkan tidak efektif. Hasil yang ada juga tidak semua bisa dikategorikan pencemar, karena ada beberapa aspek dari parameter kimia, yaitu fosfat dan nitrat justru berperan sebagai nutrient bagi kehidupan mangrove. Adapun parameter logam berat hanya disoroti aspek kadmium (Cd) dan Tembaga $(\mathrm{Cu})$ nya karena hanya kedua aspek inilah yang nilainya melebihi nilai baku mutu. 
Dalam penelitian ini parameter fisika yang diukur adalah aspek kecerahan, suhu, TSS, rasa, bau, warna dan konduktivitas. Aspek rasa, bau dan warna dapat diabaikan karena menunjukkan gejala yang sama pada semua stasiun. Aspek suhu dan kecerahan juga tidak menunjukkan perbedaan yang signifikan pada masing-masing stasiun. Menurut Odum dan Johannes (1975) dalam Supriharyono (2002) kecerahan ini dikarenakan perakaran yang kokoh dari mangrove yang memiliki kemampuan sebagai perangkap partikelpartikel sedimen, memperlambat kecepatan arus sekaligus melindungi dari pengaruh angin secara langsung yang dapat mengaduk dasar perairan yang mengakibatkan kekeruhan.

Perakaran mangrove yang kuat dan padat telah menyerap air dan mineral, tak terkecuali nitrat sehingga kadar nitrat dalam lahan basah lebih kecil daripada di dalam inlet dan outlet. Di lahan basah senyawa fosfat yang terkandung di dalam air dihilangkan melalui proses adsorbsi, absorbsi, kompleksasi dan presipitasi. Kadar BOD tertinggi yang mencapai $76 \mathrm{mg} / \mathrm{l}$ justru terdapat di dalam lahan basah. Hal ini disebabkan ketika di dalam lahan basah terjadi biodegradasi dari daun tumbuhan mangrove yang gugur kembali ke perairan. Dari biodegradasi daun selanjutnya terjadi pembusukan sehingga meningkatkan kadar BOD.

Terlihat pengurangan kadar $\mathrm{Cd}$ yang keluar melalui outlet daripada di dalam wetland meskipun kesemuanya telah berada di luar ambang batas. Oleh karena itu dapat disimpulkan bahwa lahan basah ini telah efektif dalam mengatasi pencemar dari unsur Kadmium. Akan tetapi kadar $\mathrm{Cu}$ di outlet $(0.053$ $\mathrm{mg} / \mathrm{l})$ melebihi kadar $\mathrm{Cu}$ di inlet $(0.042 \mathrm{mg} / \mathrm{l})$ maupun di dalam wetland $(0.049 \mathrm{mg} / \mathrm{l})$, sehingga lahan basah dianggap belum efektif dalam menanggulangi pencemaran oleh unsur tembaga.

\section{Analisis Kualitas Sedimen}

Hasil analisis kandungan logam berat dalam sedimen di lokasi penelitian Desa Kepetingan-Sidoarjo menunjukkan : terdapat 3 jenis logam berat $(\mathrm{Hg}, \mathrm{Cr}$, dan $\mathrm{Cd})$ yang memiliki nilai yang masih berada dibawah ambang batas yang ditentukan menurut NOAA. Terdapat 1 jenis logam berat yang melebihi batas ambang di semua stasiun pengamatan (yaitu logam Tembaga/Cu).
Diketahui bahwa meskipun melebihi ambang batas tetapi baik nilai $\mathrm{Pb}$ maupun $\mathrm{Cu}$ di outlet telah mengalami penurunan daripada di inlet maupun di lahan basah. Ini sebagai indikasi bahwa lahan basah berfungsi dengan baik. Sifat fisik dan kimia yang dimilki sedimen mangrove adalah kemampuannya untuk mengakumulasi material di lingkungan tepian pantai. Selain itu sistem perakaran mangrove turut menahan logam berat agar tetap berada di sedimen. Oleh karena itu $\mathrm{Pb}$ dan $\mathrm{Cu}$ di outlet memiliki kadar yang lebih kecil dibanding inlet dan lahan basah. Hasil ini menunjukkan bahwa perakaran mangrove cukup efektif dalam menyaring logam berat, baik dalam perairan maupun sedimen.

Hasil analisis admiralti pasut di Muara Sungai Kepetingan menunjukkan bahwa tipe pasut di perairan ini adalah tipe pasut campuran yang condong ke ganda $(F=1,45)$. Tinggi rata-rata permukaan laut adalah $-1 \mathrm{~cm}$ dengan tinggi pasang tertinggi mencapai 144 dan surut terendah $-151 \mathrm{~cm}$.

\section{KESIMPULAN DAN REKOMENDASI}

Kesimpulan yang dapat ditarik secara umum yaitu efesiensi lahan basah mangrove dalam mengeleminasi pencemaran tercapai. Faktor tercapainya efesiensi ini adalah pengurangan kadar logam berat dari mulanya di dalam stasiun inlet, mengalami pengurangan di dalam lahan basah dan akhirnya kadarnya mencapai minimal di stasiun outlet.

1. Lahan mangrove di Sidoarjo memiliki tipe dataran pantai yang merupakan jalur sempit memanjang pantai yang didominasi jenis Rhizopora sp, Avicennia Sp dan Excoecaria $S p$. Untuk area wetland seluas $7.762 \mathrm{~m}^{2}$ frekuensi kehadiran tertinggi kategori pohon, sapling dan seedling berada di dalam wetland berkisar $0.45-0.55 \%$. Species yang berada di dalam wetland adalah Avicennia $S p$ dengan Kerapatan 64 Ind/Ha dan Basal area 289.65 m² $^{2}$

2. Berdasarkan variabel kualitas air, lahan basah dinyatakan efektif dalam mengatasi pencemaran. Berdasarkan aspek fisika dibuktikan dengan kecerahan dan TSS tinggi, Aspek kimia dibuktikan dengan tereduksinya kadar BOD, nitrat dan phospat. Logam berat kadmium (Cd) dan timbal $(\mathrm{Pb})$ telah tereduksi. Akan tetapi tidak dapat mengatasi pencemaran oleh logam tembaga $(\mathrm{Cu})$. 
3. Berdasarkan variable kualitas sediment, lahan basah dinyatakan efektif dalam mengatasi pencemaran. Lahan mangrove berhasil membantu pengendapan polutan timbal $(\mathrm{Pb})$ dan tembaga $(\mathrm{Cu})$ yang dibuktikan dengan tingginya konsentrasi kedua logam tersebut di sediment di dalam lahan basah. Akan tetapi nilai $\mathrm{Pb}$ dan $\mathrm{Cu}$ masih melebihi ambang batas yang disyaratkan.

4. Kinerja lahan basah dalam mengatasi pencemaran dilakukan melalui tiga cara yaitu: a. penyerapan zat-zat polutan ke dalam akar,batang dan daun mangrove, $b$. pengendapan sediment yang dibantu oleh perakaran mangrove yang rapat, c. peran mangrove secara tidak langsung sebagai tempat hidup mikroorganisme pengurai limbah.

\section{Rekomendasi}

Agar di masa mendatang wetland dapat benar-benar berfungsi untuk mengatasi pencemaran maka harus dilakukan pengkajian lebih lanjut antara lain :

1. Melakukan perhitungan jumlah pencemar yang masuk area wetland dan jumlah yang keluar setelah melalui proses penyerapan dengan vegetasi baik itu konsentrasi di dalam sedimen maupun di dalam air sekaligus mengkaji beban pencemar di dalam air dan sedimen.

2. Mengkaji kemampuan serap dan kebutuhan tanaman akan suatu konsentrasi logam. Termasuk sifat-sifat khusus yang dimiliki tanaman yang bersangkutan kaitannya dengan kondisi eksisting area wetland dan beban pencemar yang mengenainya.

3. Dengan mengetahui kemampuan serap tanaman dan beban pencemar di sedimen atau air serta mengetahui kebutuhan tanaman akan suatu logam kemudian dapat ditentukan jumlah pohon yang harus ada di area wetland yang akan dibuat.

4. Menentukan konsep penanganan limbah yang harus diterapkan di lahan basah yang bersangkutan. Sebaiknya disesuaikan dengan ketersediaan bahan. Untuk wetland di Sidoarjo ini rekomendasi paling utama adalah perlu dibuatnya satu pintu lain di bagian wetland yang difungsikan sebagai outlet. Dengan begitu air yang masuk dan keluar lahan basah tidak saling bercampur.

5. Melakukan penelitian secara lebih eksperimental atau dalam skala laboratorium. Manfaatnya agar dapat diketahui kemampuan serap mangrove akan suatu polutan tanpa ada gangguan dari faktor luar seperti yang terjadi pada lahan mangrove alami.

\section{DAFTAR PUSTAKA}

Dumbois, Mueller And Ellenberg. 1974. Aims And Methods of Vegetation Ecology. Wiley Internasional Edition.

Cintron, G and Novelli, YS. 1984. Methodas for Studying Mangrove Structure. Hal 91-113 dalam : Snedaker,SC and Snedaker, JG (eds) The Mangrove Ecosystem : Research Methods. Unesco : Paris

Khiatuddin, Maulida. 2003. Melestarikan Sumber Daya Air Dengan Teknologi Rawa Buatan. Gadjah Mada University Press : Yogyakarta.

Lacerda, L D. 1993. The Biogeochemistry And Trace Metal Distribution of Mangrove Rhizospheres. Biotropica Vol 25 (3) : 252257.

Mac Farlane,G.R. 2003. Accumulation And Distribution of Heavy Metal In The Grey Mangrove Avicennia marina. Marine Pollution Bulletin Vol 39 : 179-186.

Silva, Carlos Augusto R. 1990. Metal Reservoir In a Red Mangrove Forest. Biotropica Vol 22 No $4: 60-68$.

Supriharyono , MS. 2002. Pelestarian Dan Pengelolaan Sumber Daya Alam di Wilayah Pesisir Tropis. Gramedia : Jakarta

Tam , N F Y. 1997. Normalisation And Heavy Metal Contamination In Mangrove. The Science of The Total Environment Vol 216 : 33-39 